Cite this: J. Mater. Chem. C, 2016, 4, 1178

Received 12th November 2015 Accepted 4th January 2016

DOI: $10.1039 /$ c5tc03774c

www.rsc.org/MaterialsC

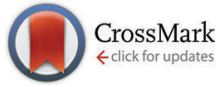

\section{Tracking a photo-switchable surface-localised supramolecular interaction via refractive index $\dagger$}

\author{
Richard M. Parker, ${ }^{\text {ab }}$ Dominic J. Wales, ${ }^{a b}$ James C. Gates, ${ }^{b}$ Peter G. R. Smith ${ }^{b}$ and \\ Martin C. Grossel ${ }^{a}$
}

\begin{abstract}
As supramolecular chemistry evolves, from the design of interactions in the solution and the solid state to applications at surfaces, there is a need for the development of analytical techniques capable of directly interrogating surface-localised supramolecular interactions. We present a proof-of-concept integrated optical Bragg grating sensor, capable of evanescently detecting small changes in refractive index at infrared wavelengths within a microfluidic system. The high spectral fidelity of the Bragg gratings combined with precise thermal compensation enables direct monitoring of the surface throughout the experiment, enabling the sensor to probe changes in situ and in real-time during surface preparation and chemical modification, and then to follow the progress of a dynamic surface-localised supramolecular interaction. In this study the sensor is assessed through the investigation of a photoswitchable inclusion complex between an azobenzene-functionalised surface and cyclodextrin in aqueous solution. The ability to investigate supramolecular interactions directly in real-time upon a planar surface via refractive index offers a valuable new tool in the understanding of complex dynamic supramolecular systems.
\end{abstract}

\section{Introduction}

Through the investigation of non-covalent intermolecular interactions between molecules, supramolecular chemistry has applied the principles of dynamic self-assembly to create complex nano-scale architectures, ${ }^{1}$ including molecular switches ${ }^{2}$ and machines. ${ }^{3-5}$ While supramolecular chemistry has traditionally focused upon the manipulation of molecules in the solution phase, leading to a diverse library of intricate structures evolving towards numerous potential applications, ${ }^{6}$ there is an increasing drive to link developments in the solution phase with solid-state crystal engineering $^{7}$ through surface-based supramolecular chemistry. ${ }^{8-10}$

Surface chemistry has been utilised throughout nanoscience for assembling layers of molecules onto a substrate; often through the use of a self-assembled monolayer (SAM). ${ }^{11}$ This approach is compatible with supramolecular systems, with the

\footnotetext{
${ }^{a}$ Chemistry Department, University of Southampton, Highfield, Southampton, SO17 1BJ, UK. E-mail: rmp53@cam.ac.uk

${ }^{b}$ Optoelectronics Research Centre, University of Southampton, Highfield, Southampton, SO17 1BJ, UK

$\dagger$ Electronic supplementary information (ESI) available: Additional data related to this publication is available at the University of Southampton data repository (http://dx.doi.org/10.5258/SOTON/385310). Solution-based NMR studies of the photo-switchable azobenzene/ $\alpha$-CD complex, integrated optical Bragg grating fabrication and interrogation methods, and additional surface-binding studies; with supporting figures. See DOI: $10.1039 / \mathrm{c} 5 \mathrm{tc} 03774 \mathrm{c}$
}

'artificial molecular muscle' reported by Liu et al. representing a notable example capable of performing mechanical work. ${ }^{12}$ Much of supramolecular and surface-based chemistry have been compatibly combined, however the challenge lies in developing robust methods for real-time interrogation of dynamic self-assembly at the surface, both non-destructively and in situ.

A wide body of analytical techniques has been developed to probe the liquid/solid interface at surfaces, ${ }^{13}$ a subset of which have been applied to the study of supramolecular interactions at a surface. Indirect measurements, such as monitoring changes in the concentration of a component in solution ${ }^{14}$ or macroscopic changes in hydrophobicity of a surface ${ }^{2}$ can reveal much about the underlying supramolecular chemistry; nevertheless there remains a need for direct, real-time measurement. While one option is fluorescence, ${ }^{15}$ the requirement for a fluorescent centre brings some limitations in terms of the types of interactions that can be studied, in addition to that of photobleaching and the difficulty in distinguishing signals originating at the surface from the surrounding media. Surface-enhanced Raman-based techniques have also shown promise in the detection of supramolecular interactions, ${ }^{16}$ however limitations in the use of structured substrates and the difficulty in resolving individual peaks within a complex host-guest system restricts their application. Thin film techniques such as ellipsometry and the quartz crystal microbalance (QCM), in addition to detecting the deposition of covalent monolayers, ${ }^{17}$ have been applied to the detection of the layer-by-layer deposition of supramolecular polymer films ${ }^{18}$ and 
nanoparticle assemblies ${ }^{19}$ or for supramolecular-based detection via a surface thin-film..$^{20,21}$ However little has been reported using these techniques for the study of molecular-scale, supramolecular monolayer surfaces.

An alternative parameter to interrogate is the refractive index of an optical mode adjacent to the surface; surface-localised refractive index measurement (typically via surface plasmon resonance, but also interferometry, ring resonators or gratings) has the benefit of being label-free and has been successfully applied to biological and to a lesser extent, chemical sensing. ${ }^{22-26}$ However, it remains highly challenging to separate a subtle change in surface-localised refractive index induced by a supramolecular interaction from fluctuations in refractive index originating from environmental phenomena (principally temperature or concentration).

Here we employ an integrated optical Bragg grating sensor, capable of evanescently detecting small changes in refractive index at infrared wavelengths, with precise localised thermal compensation. In order to critically assess the efficacy of refractive index measurement as a method to directly probe surface-localised supramolecular interactions, we chose to target the wellunderstood photo-switchable inclusion complex between aqueous $\alpha$-cyclodextrin $(\alpha-C D)$ and a surface-immobilised azobenzene (Fig. 1). This photo-switchable host-guest interaction has been used to form a switchable rotaxane, ${ }^{27,28}$ to reversibly immobilise nanotubes, ${ }^{29}$ to fabricate hydrogels that undergo reversible gelation in solution, ${ }^{30}$ and even to induce macro-scale hydrogel assembly. ${ }^{31,32}$ While such behaviour has previously been exploited in the development of photo-switchable molecular storage within mesoporous silica nanoparticles ${ }^{14}$ monitoring was achieved via the bulk release of fluorescently-tagged $\beta$-CD, rather than direct investigation of this photo-controlled interaction. Furthermore, detection of organic vapours has been reported using an optical Bragg grating refractometer, dip-coated with an allylated cyclodextrin thin-film. ${ }^{33}$

\section{Experimental details}

\subsection{Optical sensor design and interrogation}

A Bragg grating is an optical component that acts as a wavelengthselective reflector, with the characteristic Bragg peak reflected at a wavelength dependent on both the effective refractive index $\left(n_{\text {eff }}\right)$ of the waveguiding media and the intrinsic period of the grating (eqn (S1), ESI + ). We have previously reported the fabrication of an integrated-optical Bragg grating device by direct UV-writing into the photosensitive glass core of a planar silica-on-silicon substrate. ${ }^{34,35}$ The central Bragg wavelength $\left(\lambda_{\mathrm{B}}\right)$ is determined by applying a Gaussian-fit to the reflected spectrum of the grating and interrogated to sub-picometre resolution via optical fibre, with low insertion loss. This all-optical device is capable of precise refractive index measurement at infrared wavelengths (1535-1575 nm, Fig. 2). The combination of high spectral fidelity and precise temperature compensation enabled changes in the refractive index of the analyte $\left(n_{\text {anal }}\right)$ to be detected to 1 part in $10^{-6} \cdot{ }^{36}$ We have demonstrated that such

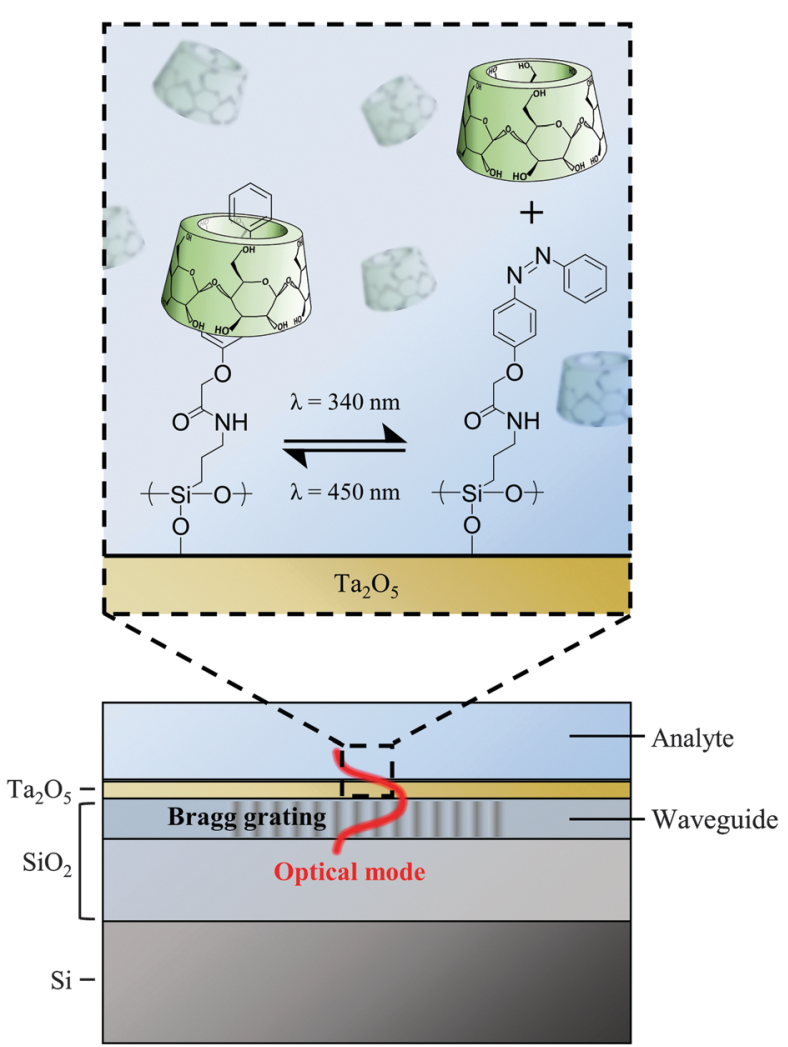

Fig. 1 A schematic of the azobenzene-modified self-assembled monolayer (top) formed on the surface of the Bragg grating sensor (bottom). The formation of the inclusion complex between the azobenzene-modified surface and an aqueous solution of $\alpha$-cyclodextrin can be dynamically triggered through photoisomerisation of the azobenzene moiety.

an integrated optical refractometer can be incorporated within a microfluidic device compatible with a wide range of solvent systems, including strong acids and bases ${ }^{37}$ where it can monitor in real-time the formation of a self-assembled monolayer at the sensor surface. ${ }^{38}$

For this work, an integrated optical waveguide circuit containing a series of four Gaussian-apodised Bragg gratings was fabricated. An $18 \mu \mathrm{m}$ deep channel was etched into the silica above three of the Bragg gratings, mechanically polished and sputtered with a thin-film of tantalum pentoxide $(80( \pm 4) \mathrm{nm})$ to increase sensitivity. ${ }^{36}$ The Bragg gratings within the etched region were used for sensing, while the fourth unetched grating acted as an independent reference for physical parameters, ${ }^{36}$ principally temperature (Fig. S4, ESI $\dagger$ ). By exposing the evanescent field of the waveguided optical mode in this way, changes in the refractive index of the surface-localised environment could be detected by the corresponding shift in the peak Bragg wavelength. Fig. 2c demonstrates this measured Bragg wavelength shift on addition of a series of bulk analytes and also highlights the enhanced sensitivity arising from the tantalum pentoxide over-layer. Temperature referencing was achieved in situ through differential analysis of the two orthogonal polarisations of the waveguide. ${ }^{39}$ This was necessary to fully decouple minute changes in the surface-localised refractive index from the thermo-optic properties $(\mathrm{d} n / \mathrm{d} T)$ of the solvent. A full description 

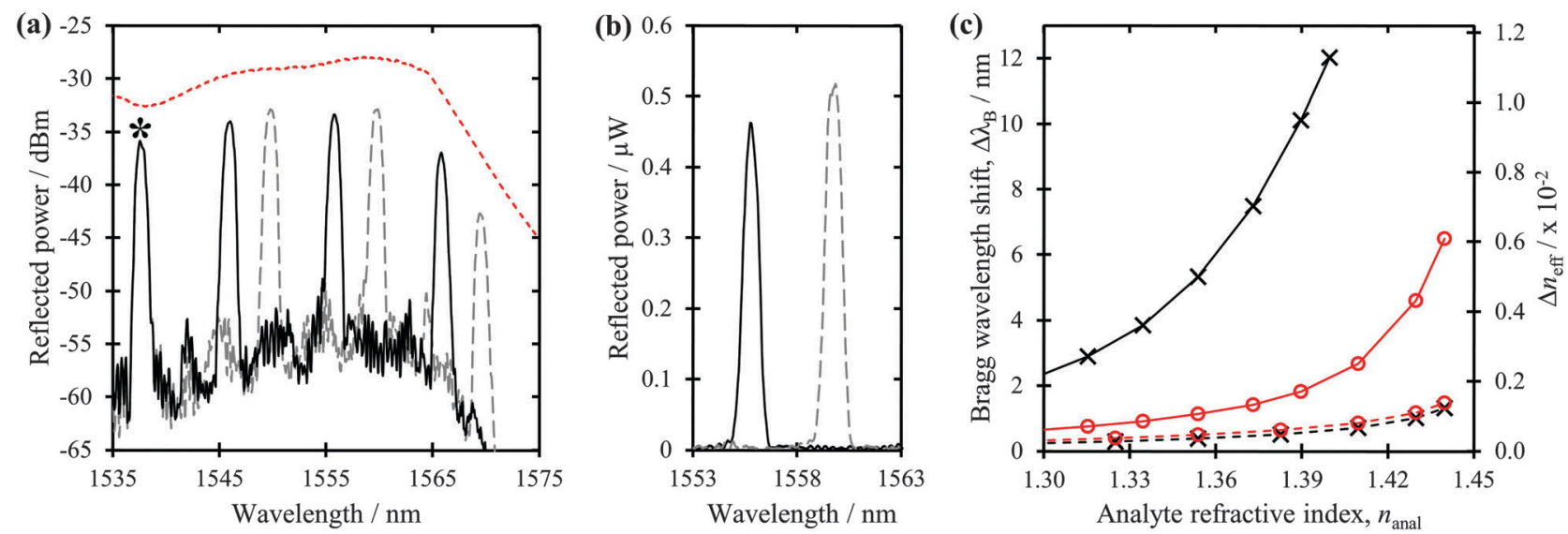

Fig. 2 (a and b) The integrated optical device consisted of four spectrally distinct Bragg gratings; an un-etched physical reference $\left(*, \lambda_{\mathrm{B}}=1538 \mathrm{~nm}\right)$ and three 'sensor' gratings $\left(\lambda_{\mathrm{B}} \approx 1546,1556,1566 \mathrm{~nm}\right)$ distributed along a linear waveguide. The reflected spectrum of the integrated optical device is plotted in air ( $n=1.00$, solid line) and in water ( $n=1.33$, dashed line) both (a) logarithmically and (b) as an extract of the data on a linear scale, showing the Gaussian profile of the Bragg peaks and low optical noise. The red line in (a) represents the background reflection spectrum from the erbium emission of the broadband source alone and it is this profile combined with reduced scattering loss that leads to the increase in the peak height in (b). (c) The sensitivity to bulk analyte refractive index $\left(n_{\text {anal }}\right)$ as measured by the average Bragg wavelength shift of the 'sensor' gratings resulting from changes in the effective refractive index ( $\Delta n_{\text {eff }}$ ) of the waveguide, for the transverse electric ( $x$, sensor) and the orthogonal, transverse magnetic (O) optical modes. The dashed-lines correspond to the bare sensor, illustrating the enhancement from the deposition of an $80 \mathrm{~nm}$ thin film of tantalum pentoxide (solid line); loss of guidance of the optical mode at a lower analyte refractive index is the cost of this increased sensitivity.

of the fabrication and interrogation of the optical device can be found within the ESI. $\dagger$

\subsection{Synthetic methods}

Commercially available compounds and solvents were obtained from Sigma-Aldrich, Fisher Scientific or Acros Organics and used as supplied, without further purification. Ethanol was distilled over calcium sulfate and used immediately. Instrumentation is detailed in the ESI.†

4-Phenylazophenol (1). 4-Phenylazophenol (1) was prepared in $71 \%$ yield by diazotising aniline and coupling at the paraposition of phenol, as previously reported. ${ }^{40,41}$

Ethyl (4-phenylazophenoxyacetate) (2). 4-Phenylazophenol $(1,0.380 \mathrm{~g}, 1.90 \mathrm{mmol}$ ) was dissolved in acetone (silica dried, $60 \mathrm{~mL})$, followed by potassium carbonate $(1.658 \mathrm{~g}, 11.9 \mathrm{mmol})$ and the mixture was warmed until complete dissolution. To this stirred solution, ethyl bromoacetate $(0.125 \mathrm{~mL}, 3.75 \mathrm{mmol})$ and sodium iodide $(0.287 \mathrm{~g}, 1.9 \mathrm{mmol}$, in $4.0 \mathrm{~mL}$ acetone) were then added. The reaction mixture was heated under reflux for $16 \mathrm{~h}$. The solvent was removed in vacuo to give an orange solid. This was subsequently extracted into diethyl ether $(3 \times 40 \mathrm{~mL})$ from water (40 $\mathrm{mL})$, before drying with magnesium sulfate, filtering and removing the solvent in vacuo. The resultant solid was purified using column chromatography (50:50 diethyl ether: light petroleum (40-60)) to give an orange solid (2, $0.307 \mathrm{~g}, 90 \%$ yield). MP: $66{ }^{\circ} \mathrm{C}$ (Lit: $\left.{ }^{42} 70{ }^{\circ} \mathrm{C}\right) .{ }^{1} \mathrm{H}$ NMR (MeOD): $\delta / p p m ~ 1.26(\mathrm{t}, J=7.1 \mathrm{~Hz}$, $\left.3 \mathrm{H},-\mathrm{CH}_{3}\right), 4.23\left(\mathrm{q}, J=7.1 \mathrm{~Hz}, 2 \mathrm{H},-\mathrm{OCH}_{2}\right), 4.77\left(\mathrm{~s}, 2 \mathrm{H},-\mathrm{OCH}_{2} \mathrm{C}(\mathrm{O})\right)$, $7.05(\mathrm{~d}, J=9.0 \mathrm{~Hz}, 2 \mathrm{H}, \mathrm{Ar}-\mathrm{H}), 7.39-7.53(\mathrm{~m}, J=7.5 \mathrm{~Hz}, 3 \mathrm{H}, \mathrm{Ar}-\mathrm{H})$, $7.83(\mathrm{dd}, J=8.2,1.7 \mathrm{~Hz}, 2 \mathrm{H}, \mathrm{Ar}-\mathrm{H}), 7.87(\mathrm{~d}, J=9.2 \mathrm{~Hz}, 2 \mathrm{H}, \mathrm{Ar}-\mathrm{H}) .{ }^{13} \mathrm{C}$ NMR (MeOD): $\delta /$ ppm 14.6 $\left(\mathrm{CH}_{3}\right), 62.6\left(\mathrm{CH}_{2}\right), 66.4\left(\mathrm{CH}_{2}\right), 116.2(\mathrm{Ar})$, 123.7 (Ar), 125.8 (Ar), $130.3(\mathrm{Ar}), 131.9$ (Ar), 148.9 (Ar), 154.17 (Ar), 162.1 (Ar), 170.6 (C(O)). IR: $\nu / \mathrm{cm}^{-1} 3068$ (C-H aromatic), 2937 (C-H), $1726(\mathrm{C}=\mathrm{O}), 1600(\mathrm{C}=\mathrm{C}$ aromatic $), 1495(\mathrm{~N}=\mathrm{N}), 1149(\mathrm{C}-\mathrm{N}), 1077$
(C-O). MS (ES $\left.{ }^{+}, \mathrm{MeOH}\right) \mathrm{m} / z 285.2\left(14.5 \%,[\mathrm{M}+\mathrm{H}]^{+}\right), 307.1(64.4 \%$, $\left.[\mathrm{M}+\mathrm{Na}]^{+}\right)$.

4-Phenylazophenoxyacetic acid (3). Ethyl (4-phenylazophenoxyacetate $)(2,0.280 \mathrm{~g}, 0.971 \mathrm{mmol})$ was dissolved in ethanol $(40 \mathrm{~mL})$. To this, an aqueous solution of sodium hydroxide (56 mM, $40 \mathrm{~mL}$ ) was added before heating the mixture under reflux for 3 hours. The reaction mixture was acidified (conc. $\mathrm{HCl}$ ) before it was extracted with diethyl ether $(3 \times 60 \mathrm{~mL})$. The combined extracts were dried with magnesium sulfate, filtered and the solvent was removed in vacuo to yield a yellow solid $\left(3,0.255 \mathrm{~g},>99 \%\right.$ yield). MP: $180{ }^{\circ} \mathrm{C}$ (Lit: ${ }^{43}$ $\left.184{ }^{\circ} \mathrm{C}\right) .{ }^{1} \mathrm{H}$ NMR (MeOD) $\delta / \mathrm{ppm} 4.72\left(\mathrm{~s}, 2 \mathrm{H},-\mathrm{OCH}_{2} \mathrm{C}(\mathrm{O})\right), 7.04$ (d, $J=9.0 \mathrm{~Hz}, 2 \mathrm{H}, \mathrm{Ar}-\mathrm{H}), 7.37-7.54(\mathrm{~m}, 3 \mathrm{H}, \mathrm{Ar}-\mathrm{H}), 7.81$ (dd, $J=8.1,1.37 \mathrm{~Hz}, 2 \mathrm{H}, \mathrm{Ar}-\mathrm{H}), 7.87$ (d, $J=9.0 \mathrm{~Hz}, 2 \mathrm{H}, \mathrm{Ar}-\mathrm{H}$ ). ${ }^{13} \mathrm{C}$ NMR (MeOD) $\delta /$ ppm $66.1\left(\mathrm{CH}_{2}\right), 116.2(\mathrm{Ar}), 123.7$ (Ar), 125.8 (Ar), 130.3 (Ar), 131.9 (Ar), 148.8 (Ar), 154.2 (Ar), 162.1 (Ar) 172.3 (C(O)). IR: v/cm $\mathrm{cm}^{-1} 3068$ (C-H aromatic), $2915(\mathrm{C}-\mathrm{H}), 2700$ broad $(\mathrm{O}-\mathrm{H}), 1706(\mathrm{C}=\mathrm{O}), 1602,1582(\mathrm{C}=\mathrm{C}$ aromatic $), 1501(\mathrm{~N}=\mathrm{N})$, $1143(\mathrm{C}-\mathrm{N}), 1085$ (C-O). MS (ES, $\mathrm{MeOH}) \mathrm{m} / \mathrm{z} 257.1$ (67.9\% [M + $\left.\mathrm{H}]^{+}\right), 279.1\left(95.2 \%,[\mathrm{M}+\mathrm{Na}]^{+}\right), 311.1(100.0 \%,[\mathrm{M}+\mathrm{Na}+$ $\mathrm{MeOH}]^{+}$). UV-vis (MeOH): $\lambda_{\max } / \mathrm{nm} 320.5,450.5$ (cis), 342.0 (trans). HRMS $\left(\mathrm{ES}^{+}, \mathrm{MeOH}\right)$ calcd for $\mathrm{C}_{14} \mathrm{H}_{13} \mathrm{~N}_{2} \mathrm{O}_{3}[\mathrm{M}+\mathrm{H}]^{+}$ 257.0921, found 257.0918, calcd for $\mathrm{C}_{14} \mathrm{H}_{12} \mathrm{~N}_{2} \mathrm{O}_{3} \mathrm{Na}[\mathrm{M}+\mathrm{Na}]^{+}$ 279.0740 , found 279.0737 .

4-Phenylazophenoxyacetyl chloride (4). 4-Phenylazophenoxyacetic acid (3, $0.100 \mathrm{~g}, 0.39 \mathrm{mmol})$ was refluxed in thionyl chloride (5 mL, $68.5 \mathrm{mmol})$ overnight under nitrogen. The remaining thionyl chloride was removed via distillation under vacuum $\left(50{ }^{\circ} \mathrm{C}\right)$, to give a red solid. A quantitative yield was assumed and the product was used immediately without further purification. $\mathrm{MS}\left(\mathrm{ES}^{+}, \mathrm{MeOH}\right) \mathrm{m} / z: 271.2(23.7 \%[\mathrm{M}+$ $\left.\mathrm{H}]^{+}\right), 293.2\left(100.0 \%[\mathrm{M}+\mathrm{Na}]^{+}\right), 325.2\left(53.2 \%[\mathrm{M}+\mathrm{Na}+\mathrm{MeOH}]^{+}\right)$, $563.3\left(13.7 \%[2 \mathrm{M}+\mathrm{Na}]^{+}\right) . \mathrm{MS}\left(\mathrm{ES}^{-}, \mathrm{MeOH}\right) \mathrm{m} / \mathrm{z}: 126.9$ 


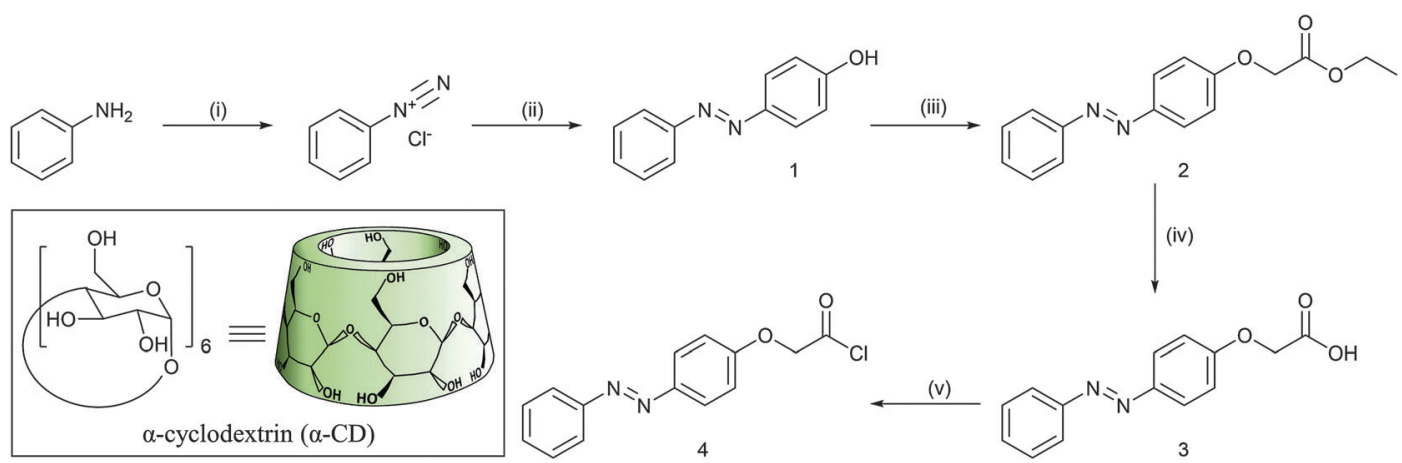

Scheme 1 The synthetic pathway for 4-phenylazophenoxyacetyl chloride, 4; (i) $\mathrm{NaNO}_{2}, \mathrm{HCl},<5{ }^{\circ} \mathrm{C}$, (ii) phenol, $<5{ }^{\circ} \mathrm{C}$, (iii) ethyl bromoacetate, $\mathrm{K}_{2} \mathrm{CO}_{3}$, $\mathrm{Nal}$, acetone, (iv) $\mathrm{NaOH}$, ethanol, and (v) thionyl chloride. Inset: Schematic and chemical structure of the macrocycle, $\alpha$-cyclodextrin.

(100.0\%, [N - 2H $\left.]^{-}\right), 255.3\left(92.9 \%,[\mathrm{~N}-\mathrm{H}]^{-}\right), 256.5$ (18.4\%, $\left.[\mathrm{N}]^{\bullet-}\right), 269.2\left(11.9 \%[\mathrm{M}-\mathrm{H}]^{-}\right)$, where ' $\mathrm{N}$ ' represents the molecular ion 3 , formed from decomposition back to the carboxylic acid. ' $M$ ' represents the molecular ion of methyl (4-phenylazophenoxyacetate), formed from the reaction of $\mathbf{4}$ with the methanol MS solvent. The formation of the methyl ester was not seen with 3 and as such can be used as an indicator for the successful synthesis of 4 (Scheme 1).

\section{Results and discussion}

Cyclodextrins are a family of macrocycles composed of glucose oligosaccharides, forming a truncated cone-like structure with hydrogen-bonding hydroxyl groups around the outer rim. They have been demonstrated to form host-guest complexes with a wide range of compounds, stabilising aromatic groups within their hydrophobic interior cavity. ${ }^{44}$ It has been reported that both the glucose-hexamer $\alpha$-cyclodextrin ( $\alpha$-CD) and glucoseheptamer $\beta$-cyclodextrin $(\beta-\mathrm{CD})$ will readily accommodate an azobenzene unit within this cavity. ${ }^{45}$ However, upon photoisomerisation of the more stable and rod-like trans-azobenzene to its bent cis-isomer the complex will dissociate. This process is reversible and upon reverting to the trans-isomer the complex can reform. ${ }^{45}$

The azobenzene motif was immobilised at the sensor surface via covalent linkage to a self-assembled monolayer of (3-aminopropyl)triethoxysilane (3-APTES). This process was realised within a microfluidic flow cell, where reagents were flowed through the micro-channel in series for both cleaning and preparative steps, functionalising the surface in situ before recontamination could occur. Following our reported protocol, ${ }^{38}$ the etched microchannel was enclosed within a stainless steel mount, sealed with a Kalrez ${ }^{\mathrm{TM}}$ O-ring. This microfluidic flow cell was networked in series via $400 \mu \mathrm{m}$ bore ethylene tetrafluoroethylene tubing with a manifold solenoid valve that allowed for the controlled flow from up to six reservoirs, pushed through the system by a solenoid diaphragm pump (Fig. S5, ESI $\dagger$ ). The pump rate and choice of reservoir was automated with LabVIEW via a USB DAQ controller. The sensor surface was cleaned by an automated series of washes with water and acetone, followed by $5.0 \mathrm{M}$ potassium hydroxide to restore the hydroxyl surface (80 $\mathrm{min})$. 3-APTES $(10 \% \mathrm{v} / \mathrm{v}$ in distilled ethanol, $12 \mathrm{~h}$ ) was flowed over this freshly prepared surface to deposit a self-assembled monolayer, affording an amine-terminated surface which was subsequently reacted with a flow of 4-phenylazophenoxyacetyl chloride, $(4,50 \mathrm{mg}$ in $70 \mathrm{~mL}$ dimethylsulfoxide in the presence of $<0.1 \mathrm{~mL}$ triethylamine, $12 \mathrm{~h}$ ). After each subsequent functionalisation of the surface, the shift in Bragg wavelength was recorded in an ethanol reference solution. It was found that the Bragg wavelength $\left(\lambda_{\mathrm{B}}\right)$ increased by $46( \pm 4)$ pm during the attachment of 3-APTES, with a further increase of $761( \pm 5)$ pm upon attachment of 4 to the surface. This corresponds to an increase in analyte refractive index $\left(\Delta n_{\text {anal }}\right)$ of $5.1( \pm 0.4) \times 10^{-4}$ and $8.4( \pm 0.1) \times 10^{-3}$ respectively, giving a cumulative refractive index shift of $\sim 8.9 \times 10^{-3}$ for the deposition of the azobenzene-terminated SAM. This observed change in refractive index is attributed to the displacement of ethanol at the surface with that of the higher refractive index monolayer. ${ }^{38}$ The attachment process was independently verified by the detection of an absorption at $348 \mathrm{~nm}$ wavelength from an analogously functionalised glass slide, characteristic of the azobenzene moiety (Fig. S1 and S6, ESI $\dagger$ ).

The azobenzene-functionalised device was installed within a casing mounted with both ultraviolet $\left(\lambda_{\max }=370 \mathrm{~nm}\right.$, $\left.\Delta \lambda_{1 / 2}=12 \mathrm{~nm}\right)$ and blue $\left(\lambda_{\max }=464 \mathrm{~nm}, \Delta \lambda_{1 / 2}=22 \mathrm{~nm}\right)$ LED light sources $\left(P_{\mathrm{d}}=40 \mathrm{~mW}\right)$; whereby switching between these two wavelengths would trigger photoisomerisation of the azobenzene surface without interference from ambient light or heating, avoiding thermal relaxation of the azobenzene moiety. A $10 \mathrm{mM}$ aqueous solution of $\alpha$-CD was added to the etched well and the device was allowed to equilibrate for several minutes under blue illumination. Then, upon switching to UV exposure, an immediate decrease in refractive index was observed that slowed over three minutes to give a well resolved Bragg wavelength decrease of $14.2( \pm 0.5) \mathrm{pm}$ in water, equating to a decrease in total analyte refractive index $\left(\Delta n_{\text {anal }}\right)$ of $2.8( \pm 0.1) \times 10^{-4}$. This decrease in refractive index corresponds to the azobenzene switching to the cis-isomer, perturbing the dynamic equilibrium at the surface towards free $\alpha$-CD (note that photoisomerisation within the complex itself is sterically inhibited ${ }^{46}$ ). By reverting to blue illumination the refractive index shift was reversed, restoring the Bragg wavelength to its original value, but over a longer 


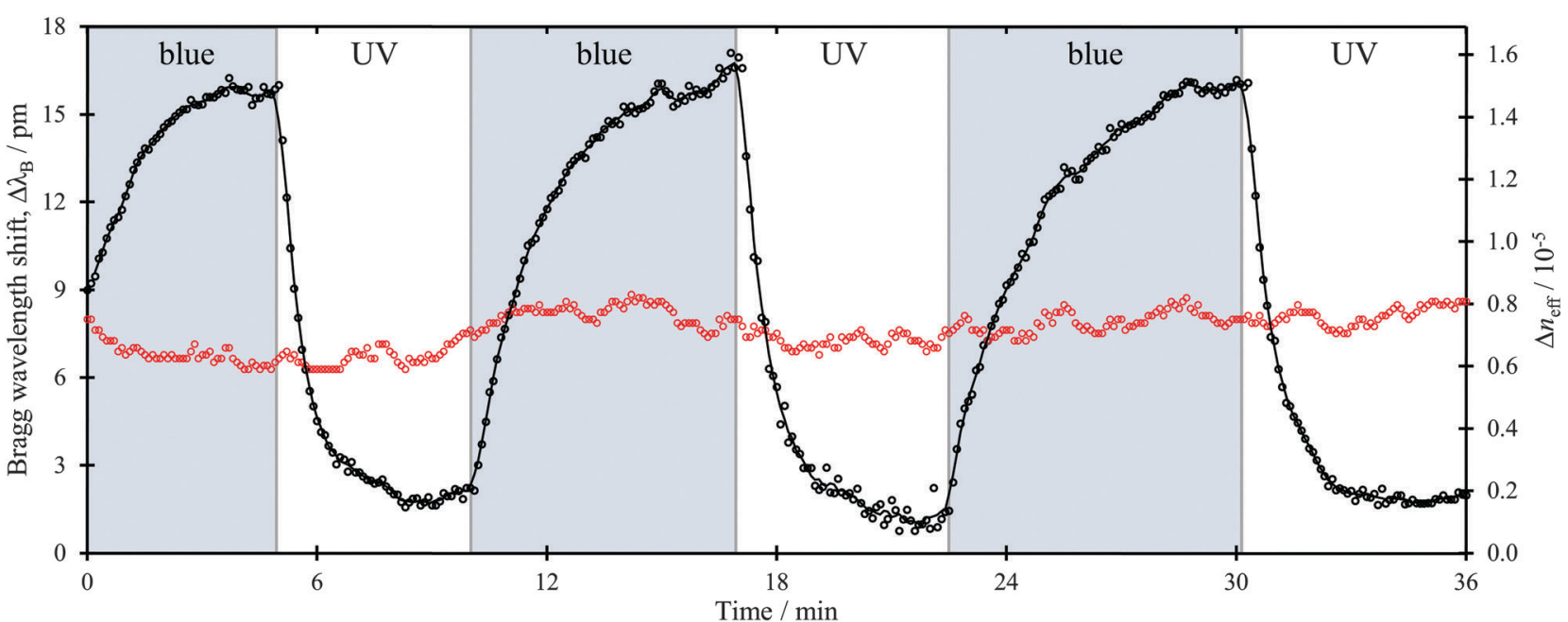

Fig. 3 The Bragg wavelength shift for the azobenzene-APTES modified sensor surface in the presence of a $10 \mathrm{mM} \alpha$-cyclodextrin solution (black circles, guideline traces the five-point moving average). Reversible photo-switching was observed upon alternating exposure to light at 360-380 nm ('UV') and 440-480 nm wavelength ('blue'). Thermal compensation was achieved through a first order approximation, derived from differential analysis of the two orthogonal polarizations of the waveguide. For comparison, the corresponding Bragg wavelength shift for the unetched reference Bragg grating is shown in red, where $\mathrm{d} \lambda_{\text {ref }} / \mathrm{d} T=10 \mathrm{pm}$ per ${ }^{\circ} \mathrm{C}$.

timescale ( $\sim 6$ minutes). The longer timescale on return to the initial trans-isomer is both consistent with that seen in the previously reported polymer system and in solution, ${ }^{47}$ indicating that photoisomerisation of the azobenzene is rate limiting. This cycle of assembly and disassembly was repeatable, as illustrated in Fig. 3.

While the magnitude of this refractive index change is smaller than that observed for the formation of the dense azobenzene monolayer, it is important to note that in the latter case a covalent bond was formed and the measurement made after replacing the reagent solution with a standardised ethanol reference. In contrast, the extent of $\alpha$-CD liberated from the planar surface is dependent on both the sterically-limited density of binding sites and the photostationary state of the azobenzene-functionalised surface. Upon disassembly of the complex, released $\alpha$-CD will be in diffusion-limited equilibrium with the surrounding solution and correspondingly will still contribute to the effective refractive index measured by the Bragg grating through a near-surface increase in concentration; however, as the evanescent component of the optical mode of the waveguide decays exponentially away from the surface such small displacements can have a disproportionate effect.

Azobenzene-functionalised polymer films are known to exhibit a measurable change in refractive index upon photoisomerisation, ${ }^{47,48}$ attributed to a change in bulk matrix density upon switching between the rod-like trans-azobenzene and the bent cis-isomer. ${ }^{49}$ As such a control experiment in the absence of $\alpha$-CD was performed; it was found that when limited to a single monolayer upon the Bragg grating surface, the effects of photoisomerisation of the azobenzene moiety were not detected in either water $\left(n_{\mathrm{D}}=1.33\right)$, or in ethanol (1.36) where the sensitivity of the refractometer is amplified by the higher refractive index of the solvent (Fig. 2c). We hypothesise that when limited to a discrete monolayer, the molecular reconfiguration upon isomerisation of azobenzene gives rise to a small change in film thickness, ${ }^{50,51}$ but the refractive index contrast for the corresponding small displacement/ingress by solvent at the photo-stationary state is not significant enough to be observed by the Bragg grating refractometer under the experimental conditions employed.

The formation of the $\alpha$-CD/azobenzene complex was confirmed in solution by ${ }^{1} \mathrm{H}$ NMR spectroscopy in $\mathrm{d}_{6}$-DMSO where, upon mixing with an equimolar solution of 4-phenylazophenoxyacetic acid (3), broadening of the $\alpha$-CD peaks was selectively observed for hydroxyl-bearing carbon atoms $\left(300 \mathrm{MHz}, \delta=4.50\left[\mathrm{t}, 6 \mathrm{H}, \mathrm{CH}_{2} \mathrm{OH}\right]\right.$, $5.45[\mathrm{~d}, 6 \mathrm{H}, \mathrm{CHOH}], 5.53[\mathrm{~d}, 6 \mathrm{H}, \mathrm{CHOH}]){ }^{31}$ This broadening corresponds to the displacement of solvent from the macrocyclic cavity and the formation of an intramolecular hydrogen-bonded structure. Subsequent re-sharpening of these peaks was observed upon exposure to UV light at $365 \mathrm{~nm}$ wavelength (Fig. S3, ESI $\dagger$ ). Complexation with $\alpha$-CD was found to have little effect on the population of the photostationary state, with the cis:trans ratio calculated to be 63:37 in solution (Fig. S2, ESI $\dagger$ ). Similarly, it was found that the presence of $\alpha$-CD did not perturb the absorption spectrum of $\mathbf{3}$ nor alter the rate of photoisomerisation in solution compared to the free system, consistent with the displacement of high energy water from the cavity driving complex formation. ${ }^{52}$

Fig. 4a illustrates the divergence of the Bragg wavelength, $\delta\left(\Delta \lambda_{\mathrm{B}}\right)$, for the $\alpha-\mathrm{CD} /$ trans-azobenzene complex and cis-azobenzene surfaces, upon increasing the $\alpha$-CD concentration from $330 \mathrm{nM}$ to $50.0 \mathrm{mM}$. As the concentration of $\alpha$-CD increases, the proportion of the $\alpha$-CD/azobenzene complex on the surface increases, further differentiating the refractive index of the two states. While no switching effect was observed when immersed in de-ionised water alone (Fig. S7, ESI $\dagger$ ), for low concentrations of $\alpha$-CD a trend towards a $4 \mathrm{pm}$ Bragg wavelength differential was observed when plotted logarithmically, implying abstraction of cyclodextrin from solution until an equilibrium with the 
(a)

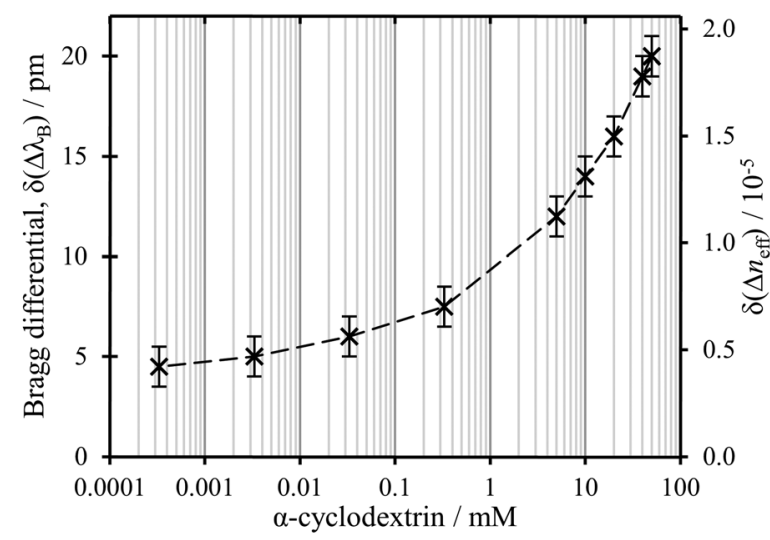

(b)

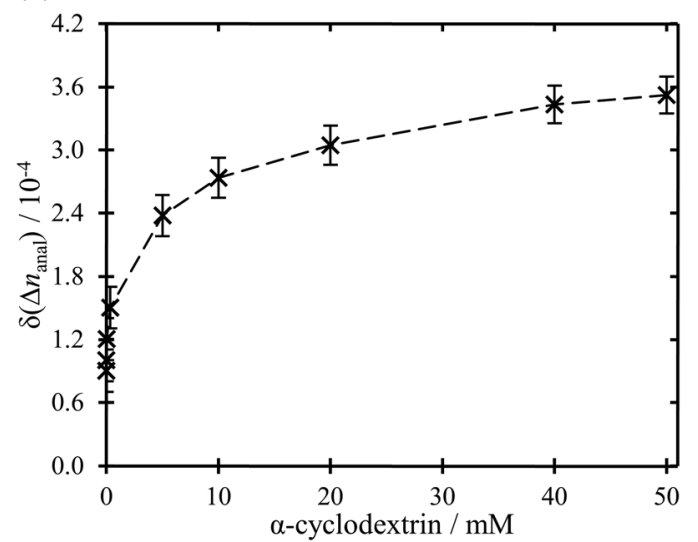

Fig. 4 (a) The average Bragg wavelength differential, $\delta\left(\Delta \lambda_{B}\right)$, between the $\alpha-C D /$ trans-azobenzene complex and cis-azobenzene surfaces, as a function of $\alpha$-cyclodextrin concentration, plotted on a logarithmic $x$-axis. This average was calculated from the independent, simultaneous measurement of three Bragg gratings in thermal equilibrium over three light cycles, with the error bars representing the standard error. (b) The difference in analyte refractive index, $\delta\left(\Delta n_{\text {anal }}\right)$, between the $\alpha-C D /$ transazobenzene complex and cis-azobenzene surfaces, after correction for the sensitivity change arising from $\mathrm{d} n / \mathrm{d} c$ of aqueous $\alpha-C D$, plotted on linear axes. Dashed lines are included as a guide for the eye only.

inclusion complex was reached. The continued increase in $\delta\left(\Delta \lambda_{\mathrm{B}}\right)$ observed at higher concentrations is attributed to the combined effect of $\mathrm{d} n / \mathrm{d} c$ of the $\alpha$-CD solution ${ }^{53}$ and the nonlinear sensitivity over large changes in analyte refractive index $\left(\mathrm{d} \lambda_{\mathrm{B}} / \mathrm{d} n_{\text {anal }}\right.$, plotted in Fig. $2 \mathrm{c}$ ). As discussed further in the ESI, $\dagger$ the combined effect is that the sensitivity to changes in surfacelocalised refractive index increases with rising $\alpha$-CD concentration (Fig. S8, ESI $\dagger$ ). The measured $\delta\left(\Delta \lambda_{\mathrm{B}}\right)$ was converted to the change in analyte refractive index, $\delta\left(\Delta n_{\text {anal }}\right)$, using the calculated sensitivity at each measured concentration (Fig. $4 \mathrm{~b})$. This showed that the rate of increase of $\delta\left(\Delta n_{\text {anal }}\right)$ is tending towards zero at the higher concentrations investigated. The gradient is estimated to be $9 \times 10^{-7}$ RIU mM ${ }^{-1}$ between 40 to $50 \mathrm{mM}$, less than the uncertainty in the refractive index measurement. As such, it is expected that any further raise in concentration would not give rise to a measurable increase, indicating saturation of the surface binding sites. It should be noted that the need to correct for $\mathrm{d} n / \mathrm{d} c$ can be avoided by switching to a reference solvent or buffer within the flow cell, as exemplified here during covalent monolayer deposition. However in the context of measuring binding at a supramolecular surface, this requires a sufficiently slow dissociation constant for disassembly to be trackable. ${ }^{38}$

Dissociation of the surface-bound complex is driven by a perturbation of the equilibrium from the trans-azobenzene guest to the less favoured cis-isomer within this dynamic system, as evidenced by the average dissociation half-life time measured to be independent of the $\alpha$-CD concentration $\left(t_{1 / 2}=32( \pm 6) \mathrm{s}\right.$ under the illumination conditions of the experiment; Fig. S9, ESI $\dagger$ ). Similarly, the association rate was found to be concentration independent at higher concentrations of $\alpha$-CD with $t_{1 / 2}=74( \pm 6) \mathrm{s}$, indicating that photoisomerisation is slower than the rate of complex formation. This trend is consistent with previous polymer-bound ${ }^{47}$ and surface-bound absorption studies (Fig. S6, ESI $\dagger$ ). However, with a $330 \mathrm{nM} \alpha-\mathrm{CD}$ solution the half-time for assembly doubled, suggesting that at this concentration and below the kinetics of host-guest complex formation dominate.

The larger $\beta$-CD has also been reported to form an inclusion complex with azobenzene. ${ }^{45}$ Despite issues of aqueous solubility above $15 \mathrm{mM}, \beta$-CD complex formation was similarly observed, however the magnitude of the Bragg wavelength shift upon dynamic formation of the complex was almost three times lower than for the equivalent $\alpha$-CD solution; for comparison $\delta\left(\Delta \lambda_{\mathrm{B}}\right)=5$ $( \pm 1) \mathrm{pm}$ for $10 \mathrm{mM} \beta$-CD. With the greater size mismatch between the azobenzene on the surface and $\beta-\mathrm{CD}$, complex formation is less favourable reducing the relative concentration of the complexed azobenzene on the surface. The effect of this is similar to lowering the overall concentration in that it reduces the surface-localised refractive index difference between the assembled and disassembled surfaces. Indeed this trend is seen in the literature, with the solution-phase association constant, $K_{\mathrm{a}}(\alpha-\mathrm{CD})$ having been reported as $2000 \mathrm{M}^{-1}$ with trans-azobenzene, but only $770 \mathrm{M}^{-1}$ for $\beta$-CD. ${ }^{32}$ This observation also extends to the much larger $\gamma$-CD, where photoisomerisation of the azobenzenefunctionalised surface resulted in a Bragg wavelength differential of only $6( \pm 1) \mathrm{pm}$ in the presence of a $25 \mathrm{mM} \gamma-\mathrm{CD}$, with more dilute solutions hard to resolve.

\section{Conclusions}

In summary, the dynamic assembly of the photo-switchable inclusion complex between an azobenzene-functionalised surface and $\alpha$-CD has been successfully tracked in real-time via direct measurement of surface-localised refractive index. The refractive index differential between the two states was found to be dependent on both the concentration and size of the cyclodextrin, with $\alpha$-CD being found to offer the largest response upon complexation. The magnitude of the surface-localised refractive index shift, when measured in situ and in dynamic equilibrium with the surrounding solution, was an order of magnitude smaller than for the deposition of the covalently-attached azobenzene monolayer. This measurement was made possible by employing a high fidelity Bragg grating sensor in conjunction 
with excellent physical referencing, in particular the unique application of optical polarisation to enable high resolution temperature referencing.

While the absolute sensitivity limit to changes in refractive index is comparable to the state-of-the-art for other types of integrated refractometers, such as SPR, the avoidance of bulk optics through the use of an optical fibre interconnect, the ability to self-reference in situ against physical effects and the use of an interrogation wavelength that does not interact with the chemistry under investigation are all significant advantages. Further, the ability to measure the absolute refractive index allows for continued measurement during significant changes in experimental conditions (e.g. changes in solvent) or between experiments not possible with 'fringe counting' based approaches used in interferometric systems. Future studies, when not ratelimited by photo-excitation of the surface-bound guest or the presence of a photostationary state, will look to employ the methodology used in SPR to quantify and compare the degree of binding and the kinetics of supramolecular chemistry on a surface with solution-based analogues.

The compatibility of integrated optical Bragg refractometers with microfluidics, combined with the ability to fabricate multiple distinct gratings within a single waveguide, offers the potential for simultaneous sensor measurements, self-referenced against both the chemical environment and physical phenomena. Applying this ability to directly probe surface-based supramolecular interactions in situ and in real-time, via near-field refractive index measurement offers a valuable new tool in the understanding of such complex dynamic supramolecular systems.

\section{Acknowledgements}

This work was supported by the UK Engineering Physical Sciences Research Council PhD Plus Fellowship for RMP (EPSRC: EP/P505739/1). DJW acknowledges EPSRC (EPSRC DTG: EP/P505119/1) and the European Regional Development Fund (ERDF) for co-financing the ISCE-Chem project (No. 4061) through the INTERREG IV A France (Channel) - England crossborder cooperation programme.

\section{References}

1 J.-M. Lehn, Proc. Natl. Acad. Sci. U. S. A., 2002, 99, 4763-4768.

2 F. Tian, D. Z. Jiao, F. Biedermann and O. A. Scherman, Nat. Commun., 2012, 3, 1207.

3 M. von Delius, E. M. Geertsema and D. A. Leigh, Nat. Chem., 2010, 2, 96-101.

4 E. R. Kay and D. A. Leigh, Angew. Chem., 2015, 54, 10080-10088.

5 S. Erbas-Cakmak, D. A. Leigh, C. T. McTernan and A. L. Nussbaumer, Chem. Rev., 2015, 115, 10081-10206.

6 D. N. Reinhoudt and M. Crego-Calama, Science, 2002, 295, 2403-2407.

7 G. R. Desiraju, J. Chem. Sci., 2010, 122, 667-675.

8 M. Cavallini, F. Biscarini, S. Léon, F. Zerbetto, G. Bottari and D. A. Leigh, Science, 2003, 299, 531.
9 A. G. Slater, L. M. A. Perdigão, P. H. Beton and N. R. Champness, Acc. Chem. Res., 2014, 47, 3417-3427.

10 J. A. A. Elemans, S. Lei and S. De Feyter, Angew. Chem., 2009, 48, 7298-7332.

11 A. Ulman, Chem. Rev., 1996, 1533-1554.

12 Y. Liu, A. H. Flood, P. A. Bonvallet, S. A. Vignon, B. H. Northrop, H.-R. Tseng, J. O. Jeppesen, T. J. Huang, B. Brough, M. Baller, S. Magonov, S. D. Solares, W. A. Goddard, C.-M. Ho and J. F. Stoddart, J. Am. Chem. Soc., 2005, 127, 9745-9759.

13 F. Zaera, Chem. Rev., 2012, 112, 2920-2986.

14 D. P. Ferris, Y.-L. Zhao, N. M. Khashab, H. A. Khatib, J. F. Stoddart and J. I. Zink, J. Am. Chem. Soc., 2009, 131, 1686-1688. 15 D. Velic and G. Kohler, Chem. Phys. Lett., 2003, 371, 483-489. 16 Y. Maeda and H. Kitano, J. Phys. Chem., 1995, 99, 487-488. 17 D. G. Kurth and T. Bein, Angew. Chem., 1992, 31, 336-338. 18 D. Li, K. Ren, H. Chang, H. Wang, J. Wang, C. Chen and J. Ji, Langmuir, 2013, 29, 14101-14107.

19 O. Crespo-Biel, B. Dordi, D. N. Reinhoudt and J. Huskens, J. Am. Chem. Soc., 2005, 127, 7594-7600.

20 P. Sun, Y. Jiang, G. Xie, X. Du and J. Hu, Sens. Actuators, B, 2009, 141, 104-108.

21 M. Brutschy, M. W. Schneider, M. Mastalerz and S. R. Waldvogel, Chem. Commun., 2013, 49, 8398-8400.

22 X. Fan, I. M. White, S. I. Shopova, H. Zhu, J. D. Suter and Y. Sun, Anal. Chim. Acta, 2008, 620, 8-26.

23 D. Bhatta, E. Stadden, E. Hashem, I. J. G. Sparrow and G. D. Emmerson, Sens. Actuators, B, 2010, 149, 233-238.

24 C. Ciminelli, C. M. Campanella, F. Dell'Olio, C. E. Campanella and M. N. Armenise, Prog. Quantum Electron., 2013, 37, 51-107.

25 M. Li, S. K. Cushing and N. Wu, Analyst, 2014, 140, 386-406.

26 M. Kutscher, M. Rosenberger, B. Schmauss, L. Meinel, U. Lorenz, K. Ohlsen, R. Hellmann and O. Germershaus, J. Biophotonics, 2016, DOI: 10.1002/jbio.201500178.

27 H. Murakami, A. Kawabuchi, R. Matsumoto, T. Ido and N. Nakashima, J. Am. Chem. Soc., 2005, 127, 15891-15899.

28 I. Willner, V. Pardo-Yissar, E. Katz and K. T. Ranjit, J. Electroanal. Chem., 2001, 497, 172-177.

29 I. A. Banerjee, L. Yu and H. Matsui, J. Am. Chem. Soc., 2003, 125, 9542-9543.

30 Y.-L. Zhao and F. Stoddart, Langmuir, 2009, 25, 8442-8446.

31 S. Tamesue, Y. Takashima, H. Yamaguchi, S. Shinkai and A. Harada, Angew. Chem., 2010, 49, 7461-7464.

32 H. Yamaguchi, Y. Kobayashi, R. Kobayashi, Y. Takashima, A. Hashidzume and A. Harada, Nat. Commun., 2011, 3, 603.

33 M. Girschikofsky, M. Rosenberger, S. Belle, M. Brutschy, S. R. Waldvogel and R. Hellmann, Anal. Chim. Acta, 2013, 791, 51-59.

34 G. D. Emmerson, S. P. Watts, C. B. E. Gawith, V. Albanis, M. Ibsen, R. B. Williams and P. G. R. Smith, Electron. Lett., 2002, 38, 1531-1532.

35 C. Holmes, J. C. Gates, L. G. Carpenter, H. L. Rogers, R. M. Parker, P. A. Cooper, F. R. M. Adikan, C. B. E. Gawith and P. G. R. Smith, Meas. Sci. Technol., 2015, 26, 112001.

36 R. M. Parker, J. C. Gates, M. C. Grossel and P. G. R. Smith, Appl. Phys. Lett., 2009, 95, 173306.

37 R. M. Parker, J. C. Gates, D. J. Wales, P. G. R. Smith and M. C. Grossel, Lab Chip, 2013, 13, 377-385. 
38 R. M. Parker, D. J. Wales, J. C. Gates, J. G. Frey, P. G. R. Smith and M. C. Grossel, Analyst, 2014, 139, 2774-2782.

39 R. M. Parker, J. C. Gates, M. C. Grossel and P. G. R. Smith, Sens. Actuators, B, 2010, 145, 428-432.

40 A. Ault, Techniques and experiments for organic chemistry, University Science Books, 4th edn, 1976.

41 M. Odabasoglu, G. Turgut and H. Kocaokutgen, Phosphorus, Sulfur Silicon Relat. Elem., 1999, 152, 27-34.

42 J. Kim and B. M. Novak, Macromolecules, 2004, 37, 8286-8292.

43 D. Jackson, PhD thesis, University of Southampton, 2008.

44 K. A. Connors, Chem. Rev., 1997, 97, 1325-1358.

45 P. Bortolus and S. Monti, J. Phys. Chem., 1987, 91, 5046-5050.

46 W. Wang and M.-Z. Wang, Polym. Bull., 2007, 59, 537-544.
47 R. M. Parker, J. C. Gates, H. L. Rogers, P. G. R. Smith and M. C. Grossel, J. Mater. Chem., 2010, 20, 9118-9125.

48 S. H. Barley, A. Gilbert and G. R. Mitchell, J. Mater. Chem., 1991, 1, 481-482.

49 H. Kudo, M. Yamamoto and T. Nishikubo, Macromolecules, 2006, 39, 1759-1765.

50 P. Ahonen, T. Laaksonen, D. J. Schiffrin and K. Kontturi, Phys. Chem. Chem. Phys., 2007, 9, 4898-4901.

51 H. Knobloch, S. Katholy, J. Hesse, H. Orendi, D. Prescher, R. Ruhmann and L. Brehmer, Mater. Sci. Eng., C, 1998, 5, 307-310. 52 J. Szejtli, Chem. Rev., 1998, 98, 1743-1754.

53 G. M. Pavlov, E. V. Korneeva, N. A. Smolina and U. S. Schubert, Eur. Biophys. J., 2010, 39, 371-379. 